\title{
Influência do Glyphosate na Dessecação de Capim-BraquiáRia e SOBRe O Desenvolvimento Inicial dA Cultura do Milho ${ }^{1}$
}

\author{
Influence of Glyphosate on Brachiaria decumbens Desiccation and on the Initial Development \\ of Corn
}

\author{
CONSTANTIN, J. ${ }^{2,7}$, MACHADO, M.H. ${ }^{3}$, CAVALIERI, S.D. ${ }^{4}$, OLIVEIRA JR., R.S..$^{2,7}$, RIOS, F.A..$^{5,7}$ e \\ ROSO, A.C. $.6,7$
}

\begin{abstract}
RESUMO - Objetivou-se com este trabalho avaliar os efeitos de doses do herbicida glyphosate, utilizadas na dessecação de manejo de Brachiaria decumbens, no sistema apliqueplante, sobre o desenvolvimento inicial da cultura do milho. O experimento foi conduzido em casa de vegetação. As unidades experimentais foram constituídas por vasos com capacidade de $5 \mathrm{dm}^{3}$, preenchidos com amostras de solo de textura franca, provenientes da camada de $0-20 \mathrm{~cm}$ de profundidade. Cada vaso foi semeado com 0,15 g de B. decumbens. Trinta e oito dias após a semeadura (DAS), procedeu-se à aplicação do glyphosate em sete doses (0, 540, 1.080, 1.620, 2.160, 2.700 e $\left.3.240 \mathrm{~g} \mathrm{ha}^{-1}\right)$. Adotou-se uma testemunha absoluta (TA) sem glyphosate e sem $B$. decumbens. Foram estabelecidos dois tipos de manejo, denominados não-recepado e recepado. No manejo não-recepado, 48 horas após a aplicação deu-se a semeadura da cultura, enquanto no manejo recepado, nessa mesma época, foi feito um corte rente ao solo das plantas de $B$. decumbens, com posterior retirada destas, seguido da semeadura da cultura. O sombreamento promovido pela presença da palha ereta de $B$. decumbens, quando esta não é roçada, causou estiolamento no milho, e as maiores doses de glyphosate aplicadas sobre $B$. decumbens apresentaram tendência de gerar reduções no desenvolvimento inicial da cultura, independentemente da presença ou ausência da palhada.
\end{abstract}

Palavras-chave: $\quad$ semeadura direta, Brachiaria decumbens, Zea mays.

\begin{abstract}
The objective of this work was to evaluate the effects of glyphosate rates used in the management desiccation of Brachiaria decumbens on the initial development of corn, under the applyplant system, under greenhouse conditions. The experimental units consisted of poliethylene vases with a capacity of $5 \mathrm{dm}^{3}$ filled with soft soil from a $0-20 \mathrm{~cm}$ depth layer. In each vase $0.15 \mathrm{~g}$ of $\boldsymbol{B}$. decumbens were sown. Thirty-eight days after sowing (DAS), glyphosate was applied at seven rates $(0,540,1.080$, 1.620, 2.160, 2.700 and 3.240 $\mathrm{g}$ a.i ha-1), plus an absolute control without glyphosate or B.decumbens. Two types of management were studied, namely: no-pruning, where the crop was sown 48 hours after application, and pruning, where 48 hours after application, the $\boldsymbol{B}$. decumbens plants were cut at soil level and the subsequent straw was removed. Shading promoted by the presence of the straw covering $\boldsymbol{B}$. decumbens plants in the absence of cutting, weakened the corn. The higher rates of glyphosate applied over B. decumbens plants tended to generate reductions at the initial development of the crop, regardless of the presence or absence of straw.
\end{abstract}

Keywords: no-till, Brachiaria decumbens, Zea mays.

1 Recebido para publicação em 30.1.2008 e na forma revisada em 31.7.2008.

Parte da tese da segunda autora apresentada ao Programa de Pós-Graduação em Agronomia da Universidade Estadual de Maringá para obtenção do título de Doutora em Agronomia, área de concentração em Proteção de Plantas.

2 Professor Associado, Núcleo de Estudos Avançados em Ciência das Plantas Daninhas (NAPD/UEM), Dep. de Agronomia, UEM, Av. Colombo, 5790 87020-900, Maringá-PR, <constantin@teracom.com.br>; ${ }^{3}$ Professora colaboradora, Dep. de Agronomia, Universidades Estadual de Londrina; ${ }^{4}$ Eng ${ }^{\circ}-A_{g r}{ }^{\circ}$, M.Sc., doutorando em Agronomia (Agricultura) da Faculdade de Ciências Agronômicas da Universidade Estadual Paulista "Júlio de Mesquita Filho", FCA/UNESP, Bolsista Fapesp; ${ }^{5}$ Graduando em Agronomia (NAPD/UEM); ${ }^{6}$ Engo $^{-}$-Agro ${ }^{0}$, mestranda do Programa de Pós-Graduação em Fitotecnia da Universidade Federal do Rio Grande do Sul na área de Herbologia; ${ }^{7}$ Bolsista do CNPq.

Planta Daninha, Viçosa-MG, v. 26, n. 3, p. 627-636, 2008 


\section{INTRODUÇÃO}

A cultura do milho ocupou no Brasil, em 2006, área em torno de 12,9 milhões de hectares, sendo responsável por uma produção de cerca de 42,5 milhões de toneladas de grãos (Conab, 2007). Mesmo considerando a média do rendimento dos Estados da região CentroSul, que foi de $3.893 \mathrm{~kg} \mathrm{ha}^{-1}$, esse rendimento foi muito inferior ao que poderia ser obtido, levando-se em consideração o potencial produtivo da cultura.

Em virtude disso, na busca por rendimentos mais altos e pela qualidade do solo como base de sustentação do sistema de produção, tem-se despertado o desafio de compreender um sistema que, além de reduzir sensivelmente a degradação do meio ambiente, permite maior retorno econômico ao agricultor (Guimarães, 2003). Assim, a expansão das áreas de cultivo sob o sistema de plantio direto, em diversas regiões do território brasileiro, tem sido notável nos últimos anos.

Segundo Almeida (1991), entre os sistemas conservacionistas, o plantio direto tem como característica a eliminação das plantas daninhas ou de cobertura com a aplicação de herbicidas antes da semeadura da cultura. Essa operação substitui as operações de revolvimento e preparo do solo, também destinadas ao controle das plantas daninhas. O controle das plantas de cobertura antes da semeadura é comumente chamado de manejo e, normalmente, é feito com herbicidas sistêmicos de ação total, como o glyphosate, com bons resultados de controle (Souza et al., 2000; Mello, 2002).

O glyphosate é um herbicida pós-emergente, pertencente ao grupo químico das glicinas substituídas, classificado como não-seletivo e de ação sistêmica. Apresenta amplo espectro de ação, o que possibilita excelente controle de plantas daninhas anuais ou perenes, tanto de folhas largas como estreitas (Galli \& Montesuma, 2005).

Segundo Maciel et al. (2003), o cultivo da soja em área de pastagem vem se concretizando em muitas regiões brasileiras, buscando expandir as fronteiras da cultura ou reformar pastagens degradadas. Na maioria dos casos, o sistema de plantio direto ou cultivo mínimo é adotado nessas áreas, com a utilização de pastagens que usualmente são dessecadas para formação da cobertura morta. Quando a pastagem é formada por $B$. decumbens, as principais vantagens para o sistema de plantio direto estão em uma maior eficiência na cobertura da superficie do solo, resultando em maior conservação de água e menor variação na temperatura deste; maior longevidade na cobertura do solo, em razão da lenta decomposição de seus resíduos; controle/minimização das doenças por ação isolante ou alelopática causada pela microflora do solo sobre os patógenos; e maior capacidade de supressão física das plantas daninhas, podendo reduzir ou até mesmo tornar desnecessário o uso de herbicidas pós-emergentes (Embrapa, 2005).

Em razão da utilização de herbicidas de manejo normalmente sistêmicos e que possuem amplo espectro, como o glyphosate e o 2,4-D, foi possivel a adoção do sistema denominado aplique-plante. Devido à natureza sistêmica desses herbicidas, o efeito sobre as plantas daninhas é lento e a cobertura demora alguns dias para morrer completamente. Assim, quando da adoção do sistema apliqueplante em decorrência da emergência da cultura, as plantas que recebem a aplicação se encontram eretas ou muitas vezes ainda não se encontram completamente dessecadas. Essa situação proporciona um sombreamento na cultura, que, juntamente com a competição por uma posição de dominância no dossel, levam ao estiolamento desta (Calegari et al., 1998). Isso se deve, segundo Radosevich et al. (1997), a algumas mudanças no desenvolvimento das plantas em decorrência do efeito competitivo, que podem ocorrer em estádios iniciais de desenvolvimento, pois estas possuem habilidade em perceber precocemente alterações no comprimento de onda luminosa resultantes da presença de palhadas ou plantas na vizinhança.

Segundo Maciel et al. (2003), há relatos de agricultores descrevendo efeitos como amarelecimento, estiolamento, redução no desenvolvimento e diminuição na produção das culturas. Outro efeito causado pela presença da palhada no início do desenvolvimento da cultura é a supressão, que é a redução temporária do crescimento das plantas. Esse efeito, embora não provoque a morte, mantém as 
plantas em estado de impossibilidade competitiva com as espécies dominantes, ou seja, seu crescimento por um determinado período fica inibido, reduzindo de forma significativa seu potencial competitivo.

Quando da dessecação de grande cobertura vegetal no momento da semeadura no sistema aplique-plante, se o produto utilizado não possuir rápida velocidade de dessecação ou promover controle ineficiente, a presença das plantas ou da palha destas pode dificultar a operação de semeadura e oferecer impedimento mecânico, dificultando a emergência da cultura. A maioria dos trabalhos realizados com o manejo de plantas de cobertura (Marques \& Benez, 2000; Constantin et al., 2000; Argenta et al., 2001; Kozlowski, 2001a,b; Valentine et al., 2001; Constantin \& Oliveira Jr., 2005; Procópio et al., 2006; Oliveira Jr. et al., 2006) avaliaram sistemas de manejo em relação à semeadura, quantidade de massa formada e seus efeitos sobre a cultura, porém nesses trabalhos o efeito do herbicida raramente foi estudado, e, segundo Coupland \& Lutman (1982), existe a possibilidade de exsudação radicular de herbicidas das plantas daninhas para a cultura, em especial o glyphosate, em decorrência da aplicação de manejo, principalmente se as raízes da cultura estiverem muito numerosas e próximas às raízes das plantas daninhas tratadas com o herbicida.

Com base no exposto, devido à necessidade de mais informações sobre o manejo no sistema aplique-plante utilizando o herbicida glyphosate, objetivou-se neste trabalho avaliar a interferência de $B$. decumbens dessecada com doses do herbicida sobre o desenvolvimento inicial do milho semeado após a dessecação.

\section{MATERIAL E MÉTODOS}

O experimento foi conduzido em casa de vegetação do Núcleo de Estudos Avançados em Ciência das Plantas Daninhas da Universidade Estadual de Maringá (NAPD/UEM), no municipio de Maringá, $P R$, entre outubro e dezembro de 2005. O experimento foi conduzido em esquema fatorial $(2 \times 7)+1$ ( 2 manejos $\times 7$ dosagens) + testemunha absoluta, em delineamento inteiramente casualizado com cinco repetições, totalizando 75 unidades experimentais.
As unidades experimentais foram constituídas por vasos com capacidade de $5 \mathrm{dm}^{3}$, preenchidos com amostras de solo de textura franca, com $69 \%$ de areia, $3 \%$ de silte e $23 \%$ de argila, provenientes da camada de $0-20 \mathrm{~cm}$ de profundidade, previamente peneiradas em malha de $2 \mathrm{~mm}$ para separação de torrões, raízes e palhas. A análise química apresentou $\mathrm{pH}$ em $\mathrm{H}_{2} \mathrm{O}=5,8 ; \mathrm{Al}^{3+}, \mathrm{H}^{+}+\mathrm{Al}^{3+}, \mathrm{Ca}^{2+}, \mathrm{Mg}^{2+}$ e K${ }^{+}$de 0,$0 ; 3,68 ; 3,91 ; 1,95$ e $0,40 \mathrm{cmol}_{\mathrm{c}} \mathrm{dm}^{-3}$, respectivamente; $\mathrm{P}=3,0 \mathrm{mg} \mathrm{dm}^{-3} ; \mathrm{e} \mathrm{C}=5,97 \mathrm{~g} \mathrm{dm}^{-3}$.

Cada vaso foi semeado com $0,15 \mathrm{~g}$ de sementes de $B$. decumbens. Aos 38 dias após a semeadura (DAS), quando as plantas estavam com três a quatro perfilhos aproximadamente, procedeu-se à aplicação de glyphosate em sete doses $(0,540,1.080,1.620,2.160,2.700 \mathrm{e}$ $3.240 \mathrm{~g} \mathrm{ha}^{-1}$ ), utilizando-se pulverizador costal pressurizado com $\mathrm{CO}_{2}$, com pressão constante de $207 \mathrm{kPa}$, equipado com três pontas tipo leque (Teejet XR 110.02), espaçadas em $0,5 \mathrm{~m} \mathrm{e}$ posicionadas a $0,5 \mathrm{~m}$ da superficie do alvo, aplicando-se o equivalente a $200 \mathrm{~L} \mathrm{ha}^{-1}$ de calda.

Foram estabelecidos dois tipos de manejo, denominados não-recepado e recepado. No manejo não-recepado, 48 horas após a aplicação deu-se a semeadura da cultura; no manejo recepado, nesse mesmo período, foi feito um corte rente ao solo e retirada das plantas de $B$. decumbens, seguido da semeadura da cultura. Para efeito de comparação, adotou-se ainda uma testemunha absoluta (TA), sem a presença de $B$. decumbens e sem aplicação de glyphosate.

Em cada vaso semearam-se cinco sementes de milho precoce (híbrido Penta) a uma profundidade de $2 \mathrm{~cm}$. A semeadura foi efetuada com sementes tratadas com Cropstar (imidacloprid + tiodicarbi) na dose de 0,35 $\mathrm{L} \mathrm{ha}^{-1} \mathrm{de}$ produto comercial. A aplicação de altas doses de glyphosate sobre $B$. decumbens foi realizada com o intuito de verificar a hipótese de transferência do herbicida das plantas-alvo para a planta não-alvo, via rizosfera compartilhada, visto que em doses menores, visualmente, é dificil a percepção de sintomas do herbicida nas plantas não-alvo.

As avaliações foram constituídas pela altura média das plantas de milho, medindo-se as plantas em cada vaso, desde a superficie do solo até a inserção da última folha

Planta Daninha, Viçosa-MG, v. 26, n. 3, p. 627-636, 2008 
completamente expandida aos $7,14,21$ e 28 dias após a semeadura (DAS); pelo diâmetro de colmo na altura do primeiro entrenó abaixo da última folha completamente expandida, realizada com auxílio de paquímetro digital; e pela massa seca de parte aérea e raízes das plantas de milho, que, juntamente com as raízes de $B$. decumbens, foram lavadas em água corrente e, posteriormente, separadas umas das outras. Os materiais (raízes e parte aérea) foram embalados separadamente em sacos de papel e secos em estufa de circulação de ar, a $60^{\circ} \mathrm{C}$, até massa constante.

Os dados foram submetidos ao teste de Hartley, com o objetivo de avaliar a homogeneidade de variâncias e o ajuste à distribuição normal dos erros. Para análise dos dados nos manejos, utilizou-se análise de variância, sendo as médias comparadas pelo teste de Tukey a 5\%; as análises de regressão foram executadas no programa estatístico SISVAR (Ferreira, 1999). A comparação dos tratamentos com a testemunha absoluta foi também realizada por meio de análise de variância, sendo as médias dos tratamentos comparadas com a testemunha pelo teste de Dunnett a 5\% de probabilidade, utilizando-se o programa estatístico Statistical Analysis System (SAS, 1999).

\section{RESULTADOS E DISCUSSÃO}

Aos 7 DAS, para a altura das plantas, o manejo não-recepado foi superior em todos os tratamentos com herbicida (Tabela 1), confirmando o fato de que, onde $B$. decumbens não é recepada, o sombreamento causaria o estiolamento das plântulas de milho, como ocorrido no trabalho realizado por Calegari et al. (1998), em que a semeadura do milho logo após a dessecação provocou estiolamento nas plantas. Na dose de $0 \mathrm{~g} \mathrm{ha}^{-1}$ de glyphosate, os manejos não apresentaram diferenças significativas. Provavelmente, a baixa altura obtida nesses tratamentos decorreu da competição entre a cultura e as plantas daninhas, uma vez que no manejo não-recepado as plantas de milho iniciaram o desenvolvimento em meio às plantas de $B$. decumbens e, no manejo recepado, a rebrota das plantas daninhas promoveu competição entre estas e a cultura.

Aos 14 DAS, o manejo recepado foi superior apenas no tratamento sem herbicida (Tabela 1), fato este já esperado, uma vez que nessa dose no manejo não-recepado a supressão inicial da cultura foi mais intensa. O manejo não-recepado apresentou valores superiores para a altura das plantas, sendo superior em todos os tratamentos com herbicida,

Tabela 1 - Altura média (cm) das plantas de milho (híbrido Penta) submetidas a doses crescentes de glyphosate nos manejos nãorecepado e recepado, aos 7, 14, 21 e 28 dias após a semeadura (DAS)

\begin{tabular}{|c|c|c|c|c|c|c|c|c|}
\hline \multirow{3}{*}{$\begin{array}{c}\text { Dose } \\
\left(\mathrm{g} \mathrm{ha}^{-1}\right)\end{array}$} & \multicolumn{8}{|c|}{ Manejo } \\
\hline & \multicolumn{2}{|c|}{7 DAS } & \multicolumn{2}{|c|}{14 DAS } & \multicolumn{2}{|c|}{$21 \mathrm{DAS}$} & \multicolumn{2}{|c|}{$28 \mathrm{DAS}$} \\
\hline & $\begin{array}{l}\text { Não- } \\
\text { recepado }\end{array}$ & Recepado & $\begin{array}{c}\text { Não- } \\
\text { recepado }\end{array}$ & Recepado & $\begin{array}{c}\text { Não- } \\
\text { recepado }\end{array}$ & Recepado & $\begin{array}{c}\text { Não- } \\
\text { recepado }\end{array}$ & Recepado \\
\hline 0 & $3,82 \mathrm{a}$ & $2,69 \mathrm{a}$ & $4,61 \mathrm{~b}$ & $6,14 \mathrm{a}$ & $6,58 \mathrm{~b}$ & $15,25 \mathrm{a}$ & $7,15 \mathrm{~b}$ & $18,88 \mathrm{a}$ \\
\hline 540 & $7,61 \mathrm{a}$ & $2,78 \mathrm{~b}$ & $10,86 \mathrm{a}$ & $8,26 \mathrm{~b}$ & $17,12 \mathrm{a}$ & $15,66 \mathrm{a}$ & $18,64 \mathrm{a}$ & $18,60 \mathrm{a}$ \\
\hline 1.080 & $7,72 \mathrm{a}$ & $3,04 \mathrm{~b}$ & $12,73 \mathrm{a}$ & $9,59 \mathrm{~b}$ & $18,72 \mathrm{a}$ & $17,35 \mathrm{a}$ & $20,51 \mathrm{a}$ & $20,55 \mathrm{a}$ \\
\hline 1.620 & $8,50 \mathrm{a}$ & $4,17 \mathrm{~b}$ & $13,65 \mathrm{a}$ & $9,89 \mathrm{~b}$ & $19,84 \mathrm{a}$ & $16,77 \mathrm{~b}$ & $21,83 \mathrm{a}$ & $19,03 \mathrm{~b}$ \\
\hline 2.160 & $9,58 \mathrm{a}$ & $4,91 \mathrm{~b}$ & $12,85 \mathrm{a}$ & $10,28 \mathrm{~b}$ & $18,60 \mathrm{a}$ & $17,14 \mathrm{a}$ & $19,96 \mathrm{a}$ & $19,89 \mathrm{a}$ \\
\hline 2.700 & $9,32 \mathrm{a}$ & $4,55 \mathrm{~b}$ & $13,22 \mathrm{a}$ & $11,04 \mathrm{~b}$ & $21,43 \mathrm{a}$ & $18,64 \mathrm{~b}$ & $23,20 \mathrm{a}$ & $21,13 \mathrm{a}$ \\
\hline 3.240 & $9,83 \mathrm{a}$ & $4,06 \mathrm{~b}$ & $13,50 \mathrm{a}$ & $9,16 \mathrm{~b}$ & $19,91 \mathrm{a}$ & $15,32 \mathrm{~b}$ & $22,41 \mathrm{a}$ & $17,56 \mathrm{~b}$ \\
\hline $\mathrm{CV}(\%)$ & \multicolumn{2}{|c|}{20,53} & \multicolumn{2}{|c|}{10,93} & \multicolumn{2}{|c|}{9,36} & \multicolumn{2}{|c|}{8,56} \\
\hline DMS & \multicolumn{2}{|c|}{1,53} & \multicolumn{2}{|c|}{1,44} & \multicolumn{2}{|c|}{2,02} & \multicolumn{2}{|c|}{2,09} \\
\hline
\end{tabular}

Médias seguidas pela mesma letra na linha não diferem entre si pelo teste de Tukey a $5 \%$. 
confirmando assim a ocorrência de estiolamento nas plantas de milho.

Aos 21 DAS, o manejo não-recepado foi superior ao recepado nas doses de 1.620, $2.700 \mathrm{e}$ $3.240 \mathrm{~g} \mathrm{ha}^{-1}$, e o manejo recepado superou apenas no tratamento sem herbicida (Tabela 1). Resultados semelhantes foram obtidos aos 28 DAS, em que o manejo recepado continuou superior ao não-recepado no tratamento sem herbicida, confirmando assim a supressão inicial da cultura no tratamento sem recepa. O manejo não-recepado foi superior nas doses de 1.620 e $3.240 \mathrm{~g} \mathrm{ha}^{-1}$, indicando a ocorrência de estiolamento da cultura. Esses resultados corroboram os encontrados por Constantin et al. (2007), que, trabalhando com diferentes épocas de dessecação de plantas daninhas antes da implantação da cultura do milho, constataram estiolamento da cultura aos 30 DAS no sistema aplique-plante.

Comparando a testemunha absoluta com os manejos, houve clara tendência de estes afetarem negativamente a altura das plantas de milho (Tabela 2). Isso demonstra que os efeitos negativos sobre a cultura independem de haver sombreamento ou herbicida no tratamento, o que leva à conclusão de que os manejos utilizados não são os mais adequados nem favorecem o desenvolvimento do milho. Esses resultados entram em concordância com os relatos de Calegari et al. (1998), Maciel (2003) e Constantin et al. (2007), que afirmam que o plantio logo após a dessecação promoveu reduções na altura da cultura em função do sombreamento promovido pelas plantas daninhas que não se encontravam totalmente mortas, ou até mesmo pela palhada ainda ereta das que foram dessecadas.

Analisando a influência das doses sobre a altura das plantas no manejo não-recepado aos 7 DAS, observou-se tendência de aumento na altura das plantas com a elevação das doses até $1.945 \mathrm{~g} \mathrm{ha}^{-1}$ (Figura 1), a partir da qual as plantas de milho passaram a apresentar menor altura, indicando a possibilidade de ocorrência de exsudação radicular de glyphosate das raízes de $B$. decumbens para as raízes da cultura. Esses resultados corroboram os de

Tabela 2 - Comparativo da altura média (cm) das plantas de milho (híbrido Penta) submetidas a doses crescentes de glyphosate nos manejos não-recepado e recepado, com a testemunha absoluta sem herbicida e sem B. decumbens, aos 7, 14, 21 e 28 DAS

\begin{tabular}{|c|c|c|c|c|c|}
\hline \multirow{2}{*}{ Manejo } & \multirow{2}{*}{$\begin{array}{c}\text { Dose } \\
\left(\mathrm{g} \mathrm{ha}^{-1}\right)\end{array}$} & \multicolumn{4}{|c|}{ Altura } \\
\hline & & 7 DAS & 14 DAS & $21 \mathrm{DAS}$ & $28 \mathrm{DAS}$ \\
\hline Não-recepado & 0 & $3,82^{(-)}$ & $4,60^{(-)}$ & $6,58^{(-)}$ & $7,15^{(-)}$ \\
\hline Não-recepado & 540 & $7,61^{(-)}$ & $10,86^{(-)}$ & $17,12^{(-)}$ & $18,64^{(-)}$ \\
\hline Não-recepado & 1.080 & $7,72^{(-)}$ & $12,73^{(-)}$ & $18,72^{\text {(ns) }}$ & $20,51^{(-)}$ \\
\hline Não-recepado & 1.620 & $8,50^{(-)}$ & $13,65^{(-)}$ & $19,84^{\text {(ns) }}$ & $21,83^{\text {(ns) }}$ \\
\hline Não-recepado & 2.160 & $9,58^{(\mathrm{ns})}$ & $12,85^{(-)}$ & $18,60^{(\mathrm{ns})}$ & $19,96^{(-)}$ \\
\hline Não-recepado & 2.700 & $9,32^{(-)}$ & $13,22^{(-)}$ & $21,43^{(\mathrm{ns})}$ & $23,20^{\text {(ns) }}$ \\
\hline Não-recepado & 3.240 & $9,83^{(\mathrm{ns})}$ & $13,50^{(-)}$ & $19,91^{\text {(ns) }}$ & $22,41^{(\mathrm{ns})}$ \\
\hline Recepado & 0 & $2,69^{(-)}$ & $6,14^{(-)}$ & $15,25^{(-)}$ & $18,88^{(-)}$ \\
\hline Recepado & 540 & $2,78^{(-)}$ & $8,26^{(-)}$ & $15,66^{(-)}$ & $18,60^{(-)}$ \\
\hline Recepado & 1.080 & $3,04^{(-)}$ & $9,59^{(-)}$ & $17,35^{(-)}$ & $20,55^{(-)}$ \\
\hline Recepado & 1.620 & $4,17^{(-)}$ & $9,89^{(-)}$ & $16,77^{(-)}$ & $19,03^{(-)}$ \\
\hline Recepado & 2.160 & $4,91^{(-)}$ & $10,28^{(-)}$ & $17,14^{(-)}$ & $19,89^{(-)}$ \\
\hline Recepado & 2.700 & $4,55^{(-)}$ & $11,04^{(-)}$ & $18,64^{\text {(ns) }}$ & $21,13^{(-)}$ \\
\hline Recepado & 3.240 & $4,06^{(-)}$ & $9,16^{(-)}$ & $15,32^{(-)}$ & $17,56^{(-)}$ \\
\hline \multicolumn{2}{|c|}{ Testemunha absoluta } & 11,65 & 16,72 & 20,94 & 24,32 \\
\hline \multicolumn{2}{|c|}{$\mathrm{CV}(\%)$} & 18,90 & 10,33 & 8,97 & 8,29 \\
\hline \multicolumn{2}{|c|}{ DMS } & 2,18 & 2,06 & 2,85 & 3,00 \\
\hline
\end{tabular}

Médias na coluna seguidas por ${ }^{(-)}$são inferiores à testemunha absoluta e ${ }^{(n)}$ não diferem da testemunha absoluta pelo teste de Dunnett a $5 \%$. 


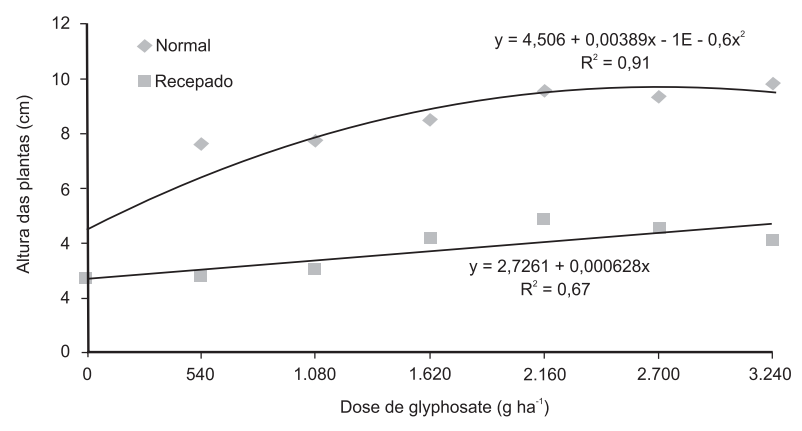

Figura 1 - Altura média (cm) das plantas de milho (híbrido Penta) submetidas a doses crescentes de glyphosate nos manejos não-recepado e recepado, aos 7 dias após a semeadura (DAS)

Vivian et al. (2007), que verificaram que o glyphosate aplicado em plantas de $B$. decumbens foi absorvido pelas raízes de Eucalyptus grandis que partilhavam da mesma zona radicular. Como no manejo recepado a mesma tendência não foi observada, provavelmente o comportamento diferenciado da altura das plantas quando submetidas ao herbicida tenha sido em função das doses aplicadas; as doses baixas proporcionaram maior rebrota das plantas daninhas e, conseqüentemente, maior competição destas com a cultura, enquanto as doses mais altas foram suficientes para controlar as plantas daninhas, não ocorrendo rebrotas e, em conseqüência, o processo de competição.

Aos 14 DAS, observou-se o mesmo comportamento das doses em relação à altura das plantas, em que acréscimos nestas promoveram incrementos na variável resposta, com ponto de máxima altura na dose de 2.004 e

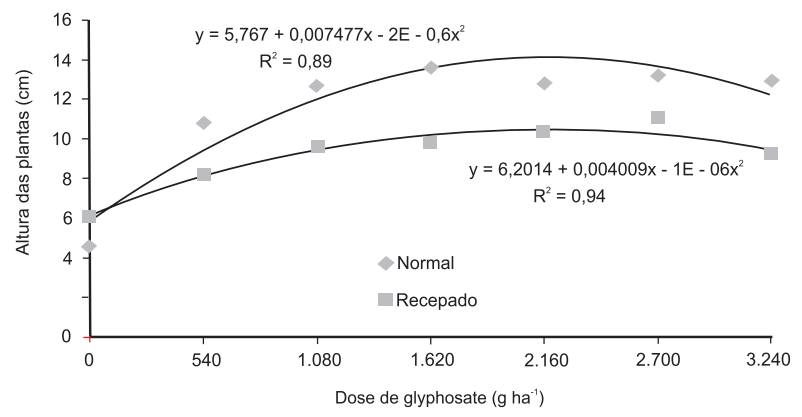

Figura 2 - Altura média (cm) das plantas de milho (híbrido Penta) submetidas a doses crescentes de glyphosate nos manejos não-recepado e recepado, aos 14 dias após a semeadura (DAS)
$1.870 \mathrm{~g} \mathrm{ha}^{-1}$ para os manejos recepado e nãorecepado, respectivamente (Figura 2 ). O mesmo comportamento das doses foi constatado aos 21 e 28 DAS, nos dois manejos (Figuras 3 e 4). A menor altura das plantas com a utilização de doses mais elevadas pode ser explicada pela exsudação do herbicida glyphosate de $B$. decumbens para as plantas de milho, via rizosfera compartilhada. Segundo Römheld (2007), a rizosfera é um importante local onde ocorre a transferência do glyphosate da plantaalvo (planta daninha) para a planta não-alvo (cultura), sendo translocado para a parte aérea, induzindo desordens.

Em relação ao diâmetro de colmo, aos 28 DAS, o manejo recepado mostrou-se superior ao não-recepado, havendo diferenças significativas nas doses de 0,540, 1.080 e

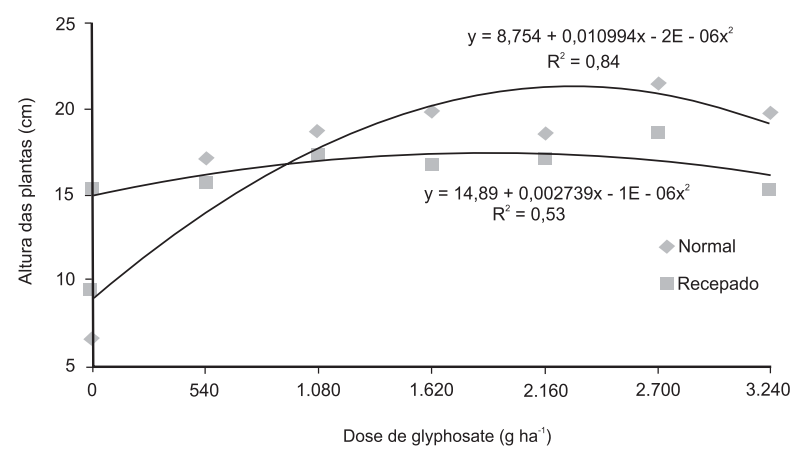

Figura 3 - Altura média $(\mathrm{cm})$ das plantas de milho (híbrido Penta) submetidas a doses crescentes de glyphosate nos manejos não-recepado e recepado, aos 21 dias após a semeadura (DAS)

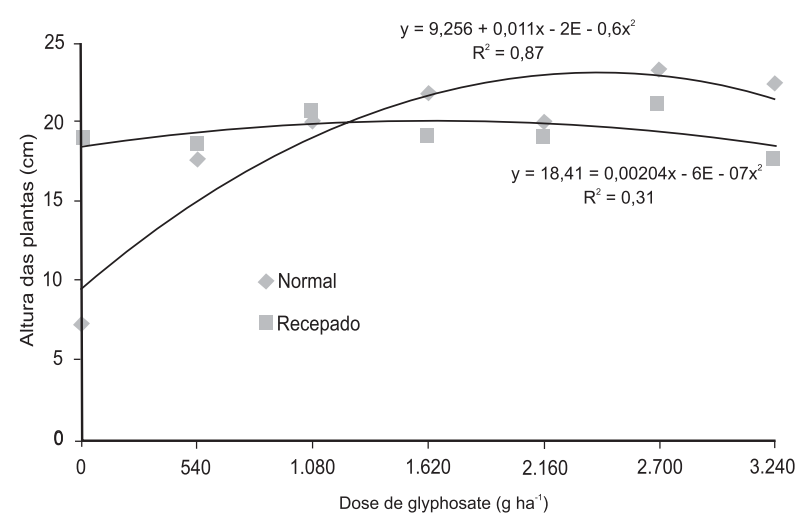

Figura 4 - Altura média (cm) das plantas de milho (híbrido Penta) submetidas a doses crescentes de glyphosate nos manejos não-recepado e recepado, aos 28 dias após a semeadura (DAS) 
2.160 $\mathrm{g} \mathrm{ha}^{-1}$ (Tabela 3). Os menores diâmetros no manejo não-recepado ocorreram, provavelmente, em conseqüência do gasto energético relacionado ao estiolamento inicial quando da emergência da cultura sob a palhada. Constantin et al. (2007) verificaram aos 30 DAS, em sistema aplique-plante, um diâmetro de colmo 13,12\% inferior em relação ao milho semeado empregando-se o sistema de manejo antecipado com aplicações seqüenciais.

Para a massa seca da parte aérea (Tabela 3), o manejo recepado foi superior nas menores doses ( 0 e $540 \mathrm{~g} \mathrm{ha}^{-1}$ ), nas quais o desenvolvimento inicial da cultura do milho foi dificultado pelas plantas daninhas, pois, nos tratamentos sem utilização de glyphosate ou com a aplicação de dose reduzida, o acúmulo de massa seca pelas plantas foi menor. Resultados semelhantes foram obtidos por Constantin \& Oliveira Jr. (2005), os quais verificaram que, em áreas com grande cobertura vegetal (acima de 40\% de cobertura do solo), culturas que são semeadas em períodos muito curtos após a dessecação apresentam redução no desenvolvimento. O manejo não-recepado foi superior nas doses de 1.080 e $3.240 \mathrm{~g} \mathrm{ha}^{-1}$, obtendo maior quantidade de massa seca; assim, o desenvolvimento da cultura não foi afetado pela presença de palha nessas doses. Na comparação entre manejos, para a massa seca de raízes (Tabela 3), na dose de $0 \mathrm{~g} \mathrm{ha}^{-1} \mathrm{o}$ manejo recepado foi superior aos demais, destacando dessa forma a importância da emergência da cultura no limpo para melhor desenvolvimento do sistema radicular.

O diâmetro de colmo e a massa seca de parte aérea apresentaram a mesma tendência observada para a variável altura em função do aumento na dose de glyphosate. Os pontos de máximo para o diâmetro de colmo foram obtidos nas doses de 1.732 e $1.641 \mathrm{~g} \mathrm{ha}^{-1}$ para os manejos não-recepado e recepado, respectivamente (Figura 5). No entanto, para a massa seca de parte aérea, os pontos de máximo acúmulo foram obtidos nas doses de $2.226 \mathrm{e}$ $3.032 \mathrm{~g} \mathrm{ha}^{-1}$ para os manejos não-recepado e recepado, respectivamente (Figura 6). O menor desenvolvimento das plantas nas maiores doses utilizadas indica novamente a possivel ocorrência de exsudação radicular das plantasalvo para a cultura. Esses dados equiparamse aos resultados obtidos por Ricordi et al. (2007), os quais comprovaram a translocação do ${ }^{14} \mathrm{C}$-glyphosate ou metabólitos via sistema radicular da planta-alvo (B. decumbens) para mudas de limão-cravo e café, 12 dias após a aplicação do ${ }^{14} \mathrm{C}$-glyphosate.

Por meio do teste de Dunnett, verificaramse, para as variáveis diâmetro de colmo, massa seca de parte aérea e raízes, diferenças significativas entre tratamentos (Tabela 4). Isso confirma a influência do herbicida e dos manejos avaliados no sistema aplique-plante.

Tabela 3 - Diâmetro médio de colmo (mm) e massa seca de parte aérea e de raízes (g) das plantas de milho (híbrido Penta), submetidas a doses crescentes de glyphosate nos manejos não-recepado e recepado, aos 28 dias após a semeadura (DAS)

\begin{tabular}{|c|c|c|c|c|c|c|}
\hline \multirow{3}{*}{$\begin{array}{c}\text { Dose } \\
\left(\mathrm{g} \mathrm{ha}^{-1}\right)\end{array}$} & \multicolumn{6}{|c|}{ Manejo } \\
\hline & \multicolumn{2}{|c|}{ Diâmetro de colmo } & \multicolumn{2}{|c|}{ MS de parte aérea } & \multicolumn{2}{|c|}{ MS de raízes } \\
\hline & Não-recepado & Recepado & Não-recepado & Recepado & Não-recepado & Recepado \\
\hline 0 & $0,93 \mathrm{~b}$ & $4,22 \mathrm{a}$ & $0,38 \mathrm{~b}$ & $12,97 \mathrm{a}$ & $0,27 \mathrm{~b}$ & $3,96 \mathrm{a}$ \\
\hline 540 & $4,21 \mathrm{~b}$ & $4,83 \mathrm{a}$ & $13,08 \mathrm{~b}$ & $15,99 \mathrm{a}$ & $4,41 \mathrm{a}$ & $4,60 \mathrm{a}$ \\
\hline 1.080 & $4,21 \mathrm{~b}$ & $5,02 \mathrm{a}$ & $20,27 \mathrm{a}$ & $17,24 \mathrm{~b}$ & $8,66 \mathrm{a}$ & $5,40 \mathrm{~b}$ \\
\hline 1.620 & $5,21 \mathrm{a}$ & $5,02 \mathrm{a}$ & $20,93 \mathrm{a}$ & $18,44 \mathrm{a}$ & $5,93 \mathrm{a}$ & $5,89 \mathrm{a}$ \\
\hline 2.160 & $5,01 \mathrm{~b}$ & $5,62 \mathrm{a}$ & $21,02 \mathrm{a}$ & $19,66 \mathrm{a}$ & $6,18 \mathrm{a}$ & $5,34 \mathrm{a}$ \\
\hline 2.700 & $5,19 \mathrm{a}$ & $5,24 \mathrm{a}$ & $20,67 \mathrm{a}$ & $19,65 \mathrm{a}$ & $6,81 \mathrm{a}$ & $7,26 \mathrm{a}$ \\
\hline 3.240 & $5,04 \mathrm{a}$ & $4,40 \mathrm{~b}$ & $22,40 \mathrm{a}$ & $16,90 \mathrm{~b}$ & $6,13 \mathrm{a}$ & $7,08 \mathrm{a}$ \\
\hline CV (\%) & \multicolumn{2}{|c|}{10,26} & \multicolumn{2}{|c|}{12,12} & \multicolumn{2}{|c|}{24,72} \\
\hline DMS & \multicolumn{2}{|c|}{0,60} & \multicolumn{2}{|c|}{2,63} & \multicolumn{2}{|c|}{1,74} \\
\hline
\end{tabular}

Médias na coluna seguidas pela mesma letra não diferem entre si pelo teste de Dunnett a $5 \%$. 


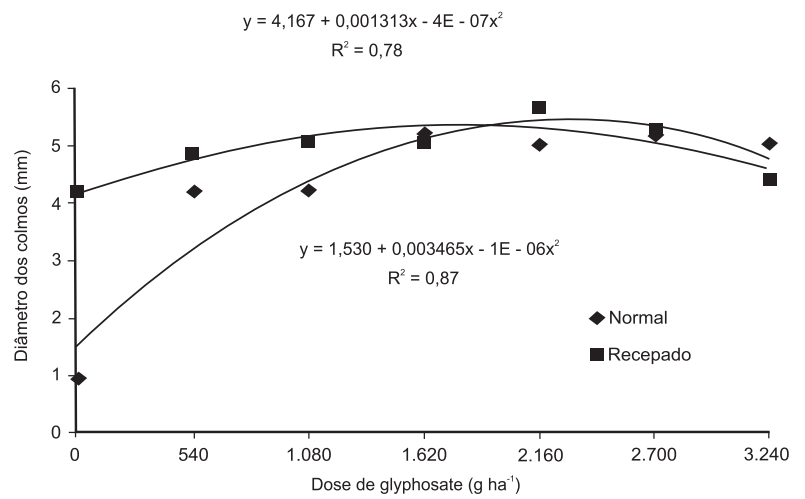

Figura 5 - Diâmetro médio de colmo (mm) das plantas de milho (híbrido Penta) submetidas a doses crescentes de glyphosate nos manejos não-recepado e recepado, aos 28 dias após a semeadura (DAS)

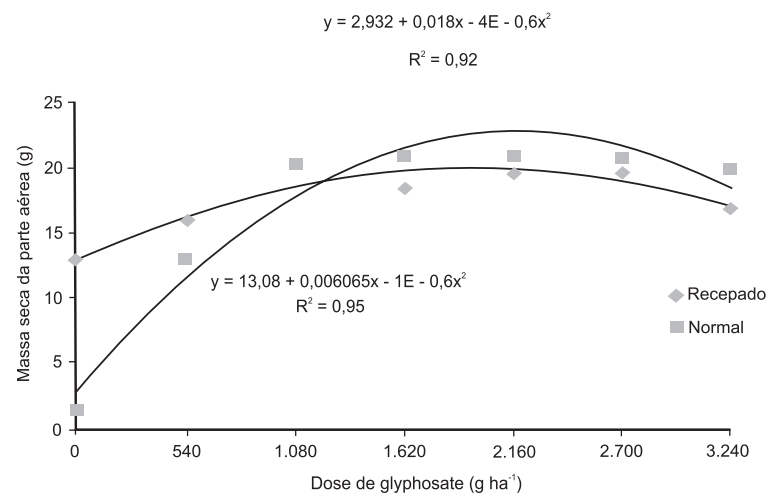

Figura 6 - Massa seca de parte aérea (g) das plantas de milho (híbrido Penta) submetidas a doses crescentes de glyphosate nos manejos não-recepado e recepado, aos 28 dias após a semeadura (DAS)

Tabela 4 - Comparativo do diâmetro de colmo (mm) e massa seca de parte aérea e raízes (g) das plantas de milho (híbrido Penta) submetidas a dosagens crescentes de glyphosate nos manejos não-recepado e recepado, com a testemunha absoluta sem herbicida e sem $B$. decumbens, aos 28 DAS

\begin{tabular}{|c|c|c|c|c|}
\hline \multirow{2}{*}{ Manejo } & \multirow{2}{*}{$\begin{array}{c}\text { Dose } \\
\left(\mathrm{g} \mathrm{ha}^{-1}\right)\end{array}$} & \multirow{2}{*}{$\begin{array}{l}\text { Diâmetro de colmo } \\
(\mathrm{mm})\end{array}$} & \multicolumn{2}{|c|}{ Massa seca } \\
\hline & & & Parte aérea & Raízes \\
\hline Não-recepado & 0 & $0,93^{(-)}$ & $12,97^{(-)}$ & $3,97^{(-)}$ \\
\hline Não-recepado & 540 & $4,21^{(-)}$ & $15,99^{(-)}$ & $4,60^{(-)}$ \\
\hline Não-recepado & 1.080 & $4,21^{(-)}$ & $17,24^{(-)}$ & $5,40^{(-)}$ \\
\hline Não-recepado & 1.620 & $5,21^{(-)}$ & $18,44^{(-)}$ & $5,89^{(-)}$ \\
\hline Não-recepado & 2.160 & $5,01^{(-)}$ & $19,66^{(-)}$ & $5,34^{(-)}$ \\
\hline Não-recepado & 2.700 & $5,19^{(-)}$ & $19,65^{(-)}$ & $7,26^{(-)}$ \\
\hline Não-recepado & 3.240 & $5,04^{(-)}$ & $16,90^{(-)}$ & $7,08^{(-)}$ \\
\hline Recepado & 0 & $4,22^{(-)}$ & $0,38^{(-)}$ & $0,27^{(-)}$ \\
\hline Recepado & 540 & $4,83^{(-)}$ & $13,08^{(-)}$ & $4,41^{(-)}$ \\
\hline Recepado & 1.080 & $5,02^{(-)}$ & $20,27^{(-)}$ & $8,66^{(-)}$ \\
\hline Recepado & 1.620 & $5,02^{(-)}$ & $20,93^{(-)}$ & $5,93^{(-)}$ \\
\hline Recepado & 2.160 & $5,62^{(-)}$ & $21,02^{(-)}$ & $6,18^{(-)}$ \\
\hline Recepado & 2.700 & $5,24^{(-)}$ & $20,67^{(-)}$ & $6,81^{(-)}$ \\
\hline Recepado & 3.240 & $4,40^{(-)}$ & $22,40^{(-)}$ & $6,13^{(-)}$ \\
\hline \multicolumn{2}{|c|}{ Testemunha absoluta } & 6,77 & 37,92 & 31,07 \\
\hline \multicolumn{2}{|c|}{ CV $(\%)$} & 9,86 & 11,10 & 19,80 \\
\hline \multicolumn{2}{|c|}{ DMS } & 0,86 & 3,77 & 2,64 \\
\hline
\end{tabular}

Médias na coluna seguidas por ${ }^{(-)}$são inferiores a testemunha absoluta pelo teste de Dunnett a $5 \%$.

Para massa seca de raízes, observou-se o mesmo comportamento no manejo não-recepado em relação ao aumento nas doses de glyphosate, em que o ponto de máximo para esta variável foi obtido na dose de $3.052 \mathrm{~g} \mathrm{ha}^{-1}$ (Figura 7). Já no manejo recepado, houve aumento na quantidade de massa seca formada pelo sistema radicular à medida que se aumentaram as doses de glyphosate.
Contudo, nas condições em que foi conduzido este trabalho, a aplicação do herbicida glyphosate para dessecação de $B$. decumbens no sistema aplique-plante promoveu reduções de altura, massa seca de parte aérea e raízes da cultura do milho quando da utilização de doses elevadas do herbicida, independentemente da presença ou ausência de palha. Nessas condições, o manejo não-recepado foi 


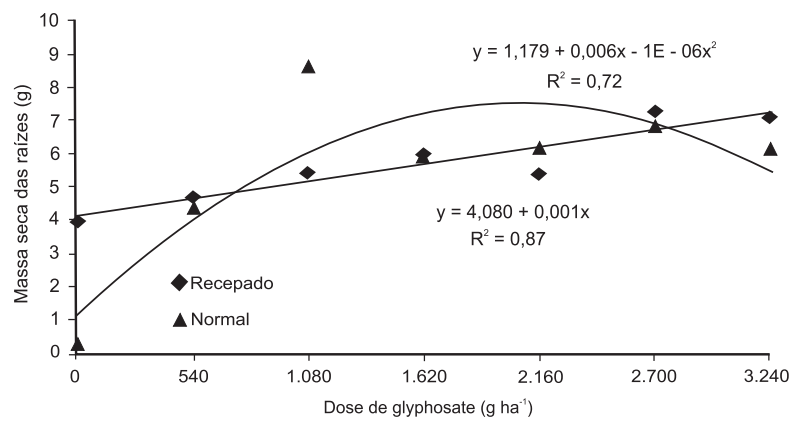

Figura 7 - Massa seca de raízes (g) das plantas de milho (híbrido Penta) submetidas a doses crescentes de glyphosate nos manejos não-recepado e recepado, aos 28 dias após a semeadura (DAS).

superado pelo recepado, devido à interferência da palhada de $B$. decumbens sobre o desenvolvimento inicial do milho, quando este foi semeado logo após a dessecação.

\section{LITERATURA CITADA}

ALMEIDA, F. S. Controle de plantas daninhas em plantio direto. Londrina: IAPAR, 1991. 34 p. (Circular, 67)

ARGENTA, G. et al. Efeitos do manejo mecânico e químico da aveia-preta no milho em sucessão e no controle do capimpapuã. Pesq. Agropec. Bras., v. 36, n. 6, p. 851-860, 2001.

CALEGARI, A. et al. Culturas, sucessões e rotações. In: Sistema Plantio Direto. O produtor pergunta, a Embrapa responde. Dourados: Embrapa-CPAO, 1998. p. 59-80. (Coleção 500 Perguntas e 500 Respostas).

CONAB. 2007. Disponível em: <http://conab.gov.br/ conabweb/index.php? $\mathrm{PAG}=131>$. Acesso em: 14 de nov. de 2007.

CONSTANTIN, J.; MACIEL, C. D. G.; OLIVEIRA JR., R. $\mathrm{S}$. Sistemas de manejo em plantio direto e sua influência sobre herbicidas aplicados em pós-emergência na cultura da soja. R. Bras. Herbic., v. 1, n. 3, p. 233-242, 2000.

CONSTANTIN, J.; OLIVEIRA JR., R. S. Dessecação antecedendo a semeadura direta pode afetar a produtividade. Inf. Agron., n. 109, p. 14-15, 2005.

CONSTANTIN, J. et al. Interação entre sistemas de manejo e de controle de plantas daninhas em pós-emergência afetando o desenvolvimento e a produtividade do milho Planta Daninha, v. 25, n. 3, p. 513-520, 2007
COUPLAND, D.; LUTMAN, P. Investigations into the movement of glyphosate from treated to adjacent untreated plants. Ann. Appl. Biol., v. 101, n. 2, p. 315-321, 1982

\section{EMPRESA BRASILERA DE PESQUISA}

AGROPECUÁRIA - EMBRAPA. 2005. Disponível em: $<$ http://www. sistemadeproducao cnptia.embrapa.br $>$. Acesso em 14 maio de 2006.

FERREIRA, D. F. Sistema de análise de variância (Sisvar). versão 4.6. Lavras: Universidade Federal de Lavras, 1999

GALLI, A. J. B.; MONTEZUMA, M. C. Alguns aspectos da utilização do herbicida glifosate na agricultura. São Paulo: Monsanto do Brasil, 2005. 60 p.

GUIMARÃES, G. L. et al. Culturas de inverno e pousio na sucessão da cultura da soja em plantio direto. Acta Sci. Agron., v. 25, n. 2, p. 339-344, 2003.

KOZLOWSKI, L. A. Aplicação seqüencial de herbicidas de manejo na implantação da cultura do feijoeiro-comum em sistema de plantio direto. R. Bras. Herbic., v. 2, n. 1, p. 4956, 2001a.

KOZLOWSKI, L. A. Eficácia de herbicidas de manejo no controle de Richardia brasiliensis em semeadura direta na cultura do feijoeiro. R. Bras. Herbic., v. 2, n. 3, p. 149-154, $2001 b$.

MACIEL, C. D. G. et al. Influência do manejo da palhada de capim-braquiária (Brachiaria decumbens) sobre o desenvolvimento inicial de soja (Glycine max) e amendoim-bravo (Euphorbia heterophylla). Planta Daninha, v. 21, n. 3, p. 365-373, 2003.

MARQUES, J. P.; BENEZ, S. H. Manejo da vegetação espontânea para a implantação da cultura do milho (Zea mays L.) em plantio direto e preparo convencional do solo. Energia Agric., v. 15, n. 1, p. 13-26, 2000.

MELLO, I. Plantio direto e o agronegócio sustentável na metade sul do Rio Grande do Sul. . B. Inf. FEBRAPDP, n. 6, p. 1-2. 2002. Disponível em: <http://www.febrapdp.org.br/ informe_6_pagina_3.htm > Acesso em: 14 de maio de 2004 .

OLIVEIRA JR., R. S. et al. Interação entre sistemas de manejo e de controle de plantas daninhas em pós-emergência afetando o desenvolvimento e a produtividade da soja. Planta Daninha, v. 24, n. 4, p. 721-732, 2006

PROCÓPIO, S. O. et al. Efeitos de dessecantes no controle de plantas daninhas na cultura da soja. Planta Daninha, v. 24, n. 1, p. 193-197, 2006.

RADOSEVICH, S.; HOLT, J.; GHERSA, C. Weed ecology: implications for management. 2.ed. New York: Wiley, 1997. 588 p.

Planta Daninha, Viçosa-MG, v. 26, n. 3, p. 627-636, 2008 
RICORDI, A. H.; TORNISIELO, V. L.; ALMEIDA, G. P. A. Translocação de ${ }^{14} \mathrm{C}$-glifosato entre Brachiaria brizantha e mudas de café (Coffea arabia) e citros (Citrus limonia Osbeck). In: SIMPÓSIO INTERNACIONAL SOBRE GLYPHOSATE, 1., 2007, Botucatu. Anais... Botucatu FCA-UNESP, 2007. p. 307-310. CD-ROM.

RÖHMHELD, V. Dinâmica do glifosato nas rizosferas das plantas-alvo e não-alvo. In: PROBLEMAS DE NUTRIÇÃO E DE DOENÇAS DE PLANTAS NA AGRICULTURA MODERNA: AMEAÇAS À SUSTENTABILIDADE?, 2007, Piracicaba. Anais... Piracicaba: IPNI, 2007. CD-ROM.

SAS Institute. Procedure guide for personal computers Version 5. Cary: 1999.
SOUZA, C. F. L. et al. Eficiência de diferentes herbicidas na dessecação de três espécies vegetais para a cobertura do solo. R. Bras. Herbic., v. 1, n. 1, p. 57-60, 2000

VALENTINI, M. H. E. et al. Épocas de manejo químico de coberturas de solo para a cultura do feijoeiro. Sci. Agric., v. 2, n. $1-2$, p. 11-16, 2001.

VIVIAN, R. et al. Potencial fitotóxico de glyphosate em eucalipto a partir da exsudação radicular de brachiaria. In: SIMPÓSIO INTERNACIONAL SOBRE GLYPHOSATE, 1., 2007, Botucatu. Anais... Botucatu: FCA-UNESP, 2007. p. 318-321. CD-ROM. 